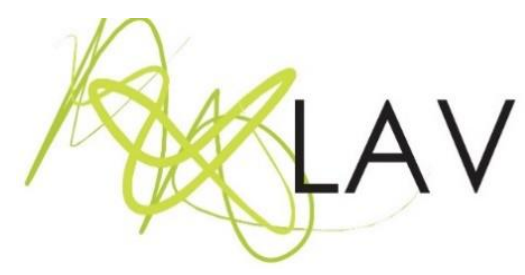

\title{
Diretores/as em ação: formação audiovisual atravessada por metodologias feministas
}

Directors in action: audiovisual training passed through feminist methodologies

Directores en acción: formación audiovisual atravesada por metodologías feministas

Lara Lima Satler

\begin{abstract}
Resumo
Este texto discute sobre algumas ações que os sujeitos envolvidos nesta investigação (eu e os participantes das disciplinas/ e do projeto de extensão Pezinho de Jatobá) dirigiram. Tal direção diz respeito tanto a função de estar à frente de uma produção audiovisual quanto de seu próprio aprender. A fim de construir processos de interformação, abarco tanto os objetivos de aprendizagem da minha prática docente, quanto as metas de aperfeiçoamento audiovisual, ambos pautados por referências de metodologias feministas. Como metodologia de pesquisa foram utilizadas a reflexão-ação, bem como os diários da professora-pesquisadora e dos discentes. Como resultados, pretende-se contribuir com a discussão sobre os atravessamentos de metodologias feministas em práticas docentes envolvendo o audiovisual.
\end{abstract}

Palavras-chave: formação de professores/as; metodologias feministas; educação da cultura visual

\begin{abstract}
This paper discusses some actions directed by people involved in this research (me and the participants of the disciplines and extension project of Pezinho from Jatobá). Directing refers to the function of being responsible for an audiovisual as well as its learning process. In order to build processes of interformation, I embrace the learning objectives in my own teaching practice and the audiovisual improvement goals, both based on references of feminist methodologies. The action-research and the diaries from the teacher-researcher and students were used as research methodologies. As results, it is intended to contribute with the discussion about the impact of feminist methodologies in teaching practices involving audiovisual.
\end{abstract}

Keywords: teachers' education; feminist methodologies; visual culture education

\section{Resumen}

Este texto discute sobre algunas acciones que los sujetos involucrados en esta investigación (yo y los participantes de las asignaturas / y del proyecto de extensión Pezinho de Jatobá) dirigieron. Esta dirección se refiere tanto a la función de estar al frente de una producción audiovisual como de su propio aprendizaje. A fin de construir procesos de interacción, abarca tanto los objetivos de aprendizaje de mi práctica docente, como las metas de perfeccionamiento audiovisual, ambos pautados por referencias de metodologías feministas. Como metodología de investigación se utilizaron la reflexión-acción, así como los diarios de la profesora-investigadora y de los discentes. Como resultados, se pretende contribuir con la discusión sobre los atravesamientos de metodologías feministas en prácticas docentes envolviendo el audiovisual.

Palabras clave: formación de professores; metodologías feministas; educación de la cultura visual. 


\section{Uma forasteira-combatente na arena da Educação da Cultura Visual}

A expressão formação audiovisual utilizada nesta reflexão é uma apropriação e também uma adaptação do campo de conhecimento e investigação que trata da Formação de Professores. É uma apropriação porque a minha formação como professora está ocorrendo por meio desta pesquisa, que se configura como um esforço sistemático de estudar sobre meu fazer docente, obtendo, por consequência, melhorias para o ensino em que atuo. Nesta apropriação, exerço a dupla função de professora-pesquisadora.

Trata-se de uma adaptação porque embora eu tenha como objetivo me formar como professora, na sala de aula articulo esse objetivo com os dos discentes, que giram em torno de aprender a produzir audiovisual. Apesar disso, essa discussão busca contribuir com o campo de conhecimento vinculado à Formação de Professores, com recorte para o ensino superior.

Diante do lugar onde atuo, uma escola de Comunicação Social, na qual estudantes têm sua atenção disputada em um currículo diversificado, o audiovisual é apenas uma das ênfases. Assim, considero imprescindível que estudantes aprendam a aprender o audiovisual, caso queiram fazer uso dele em seu percurso, o que implica em aprender como um ato contínuo de conhecê-lo e é isto que chamo de formação audiovisual.

Segundo García (1999), o conceito de formação pressupõe: a) um saber-fazer e um saberser; b) um processo de desenvolvimento pessoal envolvendo amadurecimento e compreensão das potencialidades de aprendizagem; c) e ainda atividades de formação organizacional, planejadas e realizadas institucionalmente. Embora sujeito a múltiplas perspectivas, o conceito de formação segundo o autor se vincula a uma atividade, ou seja, a uma formação para algo. Mas também,

Em primeiro lugar, a formação, como realidade conceptual, não se identifica nem se dilui dentro de outros conceitos que também se usam, tais como educação, ensino, treino, etc. Em segundo lugar, o conceito formação inclui uma dimensão pessoal de desenvolvimento humano global que é preciso ter em conta face a outras concepções eminentemente técnicas. Em terceiro lugar, o conceito de formação tem a ver com a capacidade de formação, assim como com a vontade de formação. Quer dizer, é o indivíduo, a pessoa, o responsável último pela activação e desenvolvimento de processos formativos. Isto não quer dizer, já antes o afirmamos, que a formação seja necessariamente autónoma. É através da interformação que os sujeitos - neste caso os professores - podem encontrar contextos de aprendizagem que favoreçam a procura de

Revista Digital do LAV - Santa Maria - vol. 11, n. 3, p. 138 - 161 - set./dez. 2018 ISSN 1983 - 7348 http://dx.doi.org/10.5902/1983734832834551 
metas de aperfeiçoamento pessoal e profissional (GARCÍA, 1999, p. 21-22).

Segundo o autor, a opção pelo conceito de formação (e não de educação, ensino ou treino) fornece pistas em relação ao quadro conceitual a que a discussão se vincula. Propõe ainda que, ao contrário do termo educação, a formação refere-se a ações que contribuem com o desenvolvimento pessoal e social de sujeitos adultos, como são os participantes desta investigação, na qual me incluo.

Além disso, não interessa aqui um desenvolvimento exclusivamente técnico, pois considero que nem minha ação docente o é, tampouco é apenas técnica a aprendizagem sobre a produção audiovisual. Por fim, observo que a vontade de formação pressupõe a ação participada dos sujeitos envolvidos na construção de processos de desenvolvimento e aperfeiçoamento profissional e também pessoal, que traduzo por subjetivo.

Como a formação diz respeito à minha docência e também à dos/as estudantes universitários/as que se dispuseram a colaborar com esta pesquisa, quando trato dos sujeitos envolvidos, considero objetivos de aprendizagem distintos. Apesar disso, tanto eu quanto os/as estudantes encontramo-nos em interformação, pois é este ato contínuo de aprender a aprender que investigo na minha formação docente e na discente.

Para fundamentar esta investigação, com Dias (2011) considero a proliferação de nomenclaturas envolvendo os estudos visuais, atualmente. É pertinente esclarecer a confusão gerada pela sobreposição de termos e de usos indiscriminados. Por isso, o autor sugere uma demarcação, mesmo que provisória, da Educação da Cultura Visual propondo como significado concepções pedagógicas que privilegiam a diversidade das representações visuais. Segue ainda destacando que nelas há o concatenamento e estímulo à "práticas de produção, apreciação e crítica de artes e que desenvolvem cognição, imaginação, consciência social e sentimentos de justiça" (DIAS, 2011, p. 54).

Uma vez buscando referências em outro campo, apropriações e adaptações na leitura e compreensão do debate são necessárias. O autor no trecho acima está discutindo o ensino de artes, argumentando que, para a Educação da Cultura Visual, este articula o produzir e o apreciar as obras à crítica, de modo a construir processos poéticos e interpretativos, ambos pautados pela descoberta de si, daquilo que afeta estudantes e professores em termos de sentirem-se pertencentes ao mundo que os cerca, inclusive discutir o que compreende ser justo. 
Ao me apropriar da sua argumentação, adapto-a para o contexto do audiovisual em uma escola de Comunicação Social. Assim, considerando que o audiovisual abarca o cinema, o vídeo e as imagens televisivas (DUBOIS, 2004), especulo modos de aprimoramento das práticas de ensino e aprendizagem em audiovisual que relacione tempo para a produção, a fruição e a crítica tanto na universidade quanto em um projeto de extensão, com o qual o campo da investigação dialoga. Há como objetivo que estudantes compartilhem o que aprendem com sujeitos que embora sejam vizinhos da universidade, pouco a utilizam por dificuldades de acesso aos seus serviços de ensino. Assim, a extensão e a pesquisa, caminhando com o ensino, podem estimular trocas de conhecimento capazes de ultrapassar o território da universidade.

Além disso, é a partir da Cultura Visual que observo com Martins (2012, p. 209, grifos do autor) que,

Dentre abordagens teórico-conceituais e epistemológicas as mais diversas, a cultura visual comparece não como disciplina, mas hipoteticamente como um território mais ou menos aberto, que comporta, entre seus projetos, a busca de explicitação de algumas das armas utilizadas nos diferentes embates, sobretudo aqueles dos quais os fluxos imagéticos tomem parte relevante (imagens de toda natureza, inclusive as de arte), seja na produção de sentido, na manutenção das hierarquias, no desafio a elas [...] talvez por não constituir um campo disciplinar, mas um território ou uma arena, cada aventureiro-combatente - ...e são tantos... - encontra terreno fértil para construir representações as mais diversas a seu respeito e pretender afirmar-se a partir delas.

Assim, como forasteira-combatente aventuro-me no território da construção (e desconstrução) de representações do que é ser uma professora-pesquisadora em audiovisual. Ao pôr em foco a minha formação docente, objetivo refletir sobre os processos de formação estudantil considerando, ao invés de investigar as obras em si criticando-as, questionar como tramar ações de aprendizado que articulem a produção e a apreciação à crítica, considerando a mim mesma, ao estudante e aos participantes do projeto vinculado ao campo de pesquisa como sujeitos que desejam conhecer e podem direcionar esse processo.

Assim, este texto é intitulado "Diretores/as em ação - Formação audiovisual atravessada por metodologias feministas" porque pretende discutir sobre algumas ações que os sujeitos envolvidos nesta investigação (eu e os participantes das disciplinas/ e do projeto de extensão Pezinho de Jatobá) dirigiram. Tal direção diz respeito tanto a função de estar à frente de uma produção audiovisual quanto de seu próprio aprender, a fim de construir processos de interformação, abarcando tanto os objetivos de aprendizagem da minha 
prática docente, quanto as metas de aperfeiçoamento audiovisual, pautados por metodologias feministas. Portanto, pretendo construir a discussão tendo como perspectiva estes dois aspectos simultaneamente. Por fim, além de discutir sobre as ações dirigidas pelos sujeitos, interessa-me as reflexões que eles/as construíram sobre elas.

Assim, para esse texto serão observadas as imagens audiovisuais, os diários de aula (OLIVEIRA, 2011), todos realizados pelos sujeitos envolvidos nesta pesquisa, durante a oferta de duas disciplinas de Núcleos Livres - NLs (Saberes Audiovisuais Colaborativos, ofertado em 2012/1; Aprendizagens Audiovisuais Cotidianas, em 2012/2), na Universidade Federal de Goiás. A produção dos dados deste trecho da pesquisa ocorreu no contexto de aula, dentro de uma metodologia de pesquisa-ação (THIOLLENT, 1985), que atualizamos para reflexão-ação, e mesmo que todos/as tenham consentido em participar como sujeito da pesquisa, assinando também o Termo de Autorização de Uso de Imagem e Depoimentos, opto por nomes fictícios para os/as envolvidos/as.

A partir dessa breve delimitação, abarco a perspectiva reflexiva da pesquisa em educação da cultura visual, que trata "as imagens e os artefatos visuais como vivências que articulam significados existenciais e simbólicos" (MARTINS; TOURINHO, 2013, p. 63). Desse modo, ao amparar metodologicamente a reflexividade, abarco também a pesquisa-ação (THIOLLENT, 1985), combinando-a ao espaço para vivências subjetivas, minhas e estudantis, em grupo sobre o meu fazer docente e as aprendizagens.

Desse modo, os diários de aula se mostraram uma ferramenta de pesquisa capaz de fazer emergir a reflexão dos envolvidos no campo, abarcando espaço para registro de suas próprias descobertas deflagradas a partir de dispositivos de aprendizagem propostos nas aulas e na extensão. Com Oliveira (2013, p. 226-227) tenho o viés em que os diários de aula serviram à investigação,

A perspectiva da cultura visual nesse projeto de pesquisa, mais que um conceito operacionalizável, assume um posicionamento político e epistemológico. Trata da maneira como nos relacionamos com as visualidades, sejam elas da história da arte, sejam do cinema, das histórias em quadrinhos (HQs), da publicidade, da moda, do design, etc. Não está focado apenas no olhar do observador nem no objeto/visualidade observada, e sim no que podemos construir no processo, no percurso, nesse espaço de interstício entre o que vemos e o que nos olha. Essa construção discursiva não diz respeito a algo que possa ser da ordem da representação, da ilustração de uma identidade, e sim quer ser pensada a partir de uma experimentação. 
Nesta direção, pensar meu papel como docente, nesta pesquisa, não é a partir de representações do que é ser uma professora, que lida com o audiovisual no ensino superior. Antes interessa-me experimentar este lugar, refletindo sobre as imagens que eu e os estudantes trazem sobre a o aprender. Portanto, os diários de aula funcionam como um suporte para o registro da reflexão sobre as experimentações, e ao ser lido em grupo gera diversos vieses de um mesmo acontecimento, podendo produzir o que Dewey (1981) conceituou ser experiência, isto é, a ação vivida maturada pela reflexão.

Tal como Oliveira (2013), o uso dos diários serve às aprendizagens audiovisuais não a partir do que este representa para quem vê ou para a produção em si mesma, mas a partir da experiência gerada. Por isso, esta investigação considera os processos e percursos construídos por mim e pelos sujeitos envolvidos em criar e interpretar audiovisual. É esta orientação teórico-metodológica que conduz a discussão aqui proposta.

\section{Luz, câmera, formação}

Sobre a ação dos sujeitos envolvidos nesta pesquisa, observo a pertinência do enfoque de Miranda (2015a) quanto às exigências da atualidade no trabalho (e por consequência) na formação desdec, com/sobre imagens. Aproprio-me da sua discussão, localizada no ensino de artes visuais, para pensar a formação audiovisual nas duas perspectivas mencionadas: a da minha ação docente nela e a do aprendizado estudantil. Segundo o autor, não é possível escapar à nova relação contemporânea com as imagens e não se pode pensar nesta relação como se ela fosse a mesma de cem anos atrás. Atualmente,

a produção de experiências, a geração de espaços de relação, a promoção de diversas formas de participação criativa são novas maneiras que nem sempre remetem ao objeto material visível, aquele que parece articular a tradição educativa (MIRANDA, 2015a, p. $16-17)^{1}$

Isso porque os meios digitais disponíveis a partir do que o autor nomeou de rede 2.0, concentram-se na efemeridade da experiência mais do que na estabilidade ou permanência da obra artística ou, para esta investigação, da produção audiovisual finalizada. Apropriando-me de tal perspectiva, neste NL objetivo uma formação audiovisual que deflagre as experiências dos sujeitos, considerando o audiovisual como meio de relacionar os participantes entre si. Assim, o foco da formação não está no audiovisual como obra final, objeto ou produto, mas na ação participada dos sujeitos que mediados por ele

\footnotetext{
1 "La producción de experiencias, la generación de espacios de relación, la promoción de diversas formas de participación creativa, son nuevas maneras que no siempre remitem al objeto material visible, aquel que parece articular la tradición educativa".
}

Revista Digital do LAV - Santa Maria - vol. 11, n. 3, p. 138 - 161 - set./dez. 2018 ISSN 1983 - 7348 http://dx.doi.org/10.5902/1983734832834551 
constroem experiências de relação e a partir delas suas aprendizagens. Mas no que isso implicou?

Em primeiro lugar, implicou em compreender alguns aspectos que me provocam incômodo no exercício da docência onde atuo. Formada por uma imagem construída do que é ser professora no ensino superior, minha docência transitou entre a imitação de professores/as que admirei na minha jornada estudantil e acadêmica e a negação daqueles/as que pouco contribuíram com meus processos de conhecimento.

García (1999, p. 33) esclarece que, na formação de professores no ensino superior, há uma hegemonia da orientação conceitual acadêmica que "enfatiza o papel do professor como especialista numa ou em várias áreas disciplinares", por isso os processos de formação que vivi na universidade foram "de transmissão de conhecimentos" focados "no domínio de conceitos e estrutura disciplinar da matéria".

Mesmo que o autor esteja tratando de um contexto de licenciatura, observo que a orientação acadêmica é praticada também em cursos de bacharelados, como o que cursei. García (1999) argumenta ainda que além de privilegiar o domínio dos conteúdos por meio da especialização das disciplinas, a orientação acadêmica se caracteriza por uma considerável ênfase na formação científica em detrimento da pedagógica. Assim, a orientação acadêmica influencia minha docência uma vez que os/as professores/as que tive durante minha trajetória escolar a praticavam e por imitação a aprendi, mesmo sem o saber.

Carvalho (2012) realiza uma pesquisa com professores/as bacharéis dos cursos de Jornalismo e Relações Públicas e da habilitação de Publicidade e Propaganda em Instituições do Ensino Superior (IES), em Brasília, advertindo para a necessidade dos/as docentes do campo refletirem sobre suas práticas pedagógicas, uma vez que eles/as têm historicamente pouca formação para atuar no ensino superior.

Contudo, o agravante de uma formação de professores insuficiente não está apenas nas práticas pedagógicas, mas em certo desconhecimento sobre as orientações conceituais que conjugam ideias acerca delas, do ensino superior, da função do/a professor/a neste contexto, da formação estudantil, do currículo, etc.

Tais orientações trazem perspectivas teóricas distintas não apenas quanto ao exercício pedagógico da docência, mas também quanto à formação em termos amplos (incluindo a dimensão pessoal, o desenvolvimento global, a perspectiva técnica, a vontade da formação, bem como a necessidade de construir tudo isso entre sujeitos, que é a 
interformação). Portanto, busco mapear outras orientações conceituais que foram referências para minha ação docente.

Assim, outra orientação conceitual que marcou o meu percurso acadêmico foi a tecnológica, nos termos propostos por García (1999). No ensino da Comunicação Social, ela está em tensão com uma orientação acadêmica de viés humanista. A orientação tecnológica, que no Brasil é traduzida por tecnicista, pressupõe um enfoque reducionista do ensino ao privilegiar o saber técnico e profissionalizante dos egressos. De acordo com García (1999, p. 36), na formação de professores/as, esta orientação pressupõe programas baseados em destrezas e competências para o ensino, encarando-o como uma ciência aplicada e o docente como um técnico "capaz de seleccionar e decidir qual a competência mais adequada em cada situação".

Ainda outra orientação conceitual referência para meu percurso foi a prática. De acordo com o autor, na orientação conceitual prática a formação docente se dá pela observação e experiência, bem como pelo reconhecimento dos saberes prévios que cada um/a possui sobre ser professor/a. Uma vez que o/a professor/a já traz consigo um conhecimento prévio sobre a ação docente, ele/a procura observá-la e torná-la experiência, ou seja, dar sentido a este conhecimento por meio da reflexão sobre a sua prática. Ainda segundo o autor, há distintas formas de reflexão em relação à ação:

a) a introspecção por meio de análise das experiências pessoais de professores/as ajuda seu desenvolvimento profissional quando debatidas em grupo. Trata-se de uma reflexão pouco atrelada à ação;

b) o exame está mais próximo da ação na medida em que estuda as referências do/a professor/a quanto aos acontecimentos do passado, presente e futuro na vida da classe;

c) a indagação está vinculada à investigação-ação por meio da qual o/a professor/a analisa sua prática, buscando meios de melhorá-la;

d) a espontaneidade é a que mais se relaciona com a prática, pois abarcam as reflexões na ação, ou seja, os pensamentos dos/as professores/as durante as improvisações, solução de problemas e divergências em sala.

A indagação (que inicia um processo de mudança para o meu aperfeiçoamento como professora) e a espontaneidade (por meio de registros em diários de aula) são as opções mais aproximadas do conceito de reflexão assumido nesta pesquisa. Por isso, as orientações acadêmica e tecnológica que tive contato na minha trajetória estudantil são 
refletidas nesta indagação-espontânea, colocando em questão os alcances e os limites da minha ação docente. Para sistematizar estas reflexões fiz uso do diário como instrumento de pesquisa.

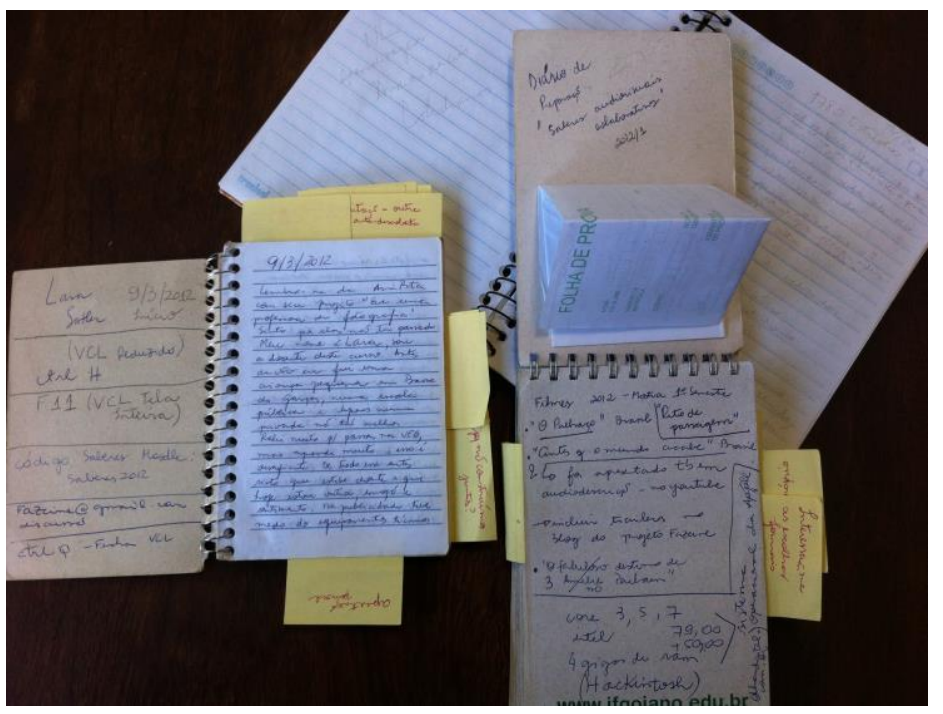

Figura 01. Meus diários de aula (Foto da autora, 2015).

A figura 1 representa um pouco do que foi montar estas duas disciplinas novas de NL: um caótico de notas, rascunhos e aprendizagens. Anos depois destas ofertas, debruço-me sobre estes diários a fim de sistematizar as indagações-espontâneas que, naquele momento, exigiram-me experimentar outro espaço-tempo para a minha docência. Algumas das quais cito abaixo:

Na quinta última vivi uma experiência que me fez pensar muito sobre a minha pesquisa. Estávamos o Carlos, o Renato e eu preparando o seminário e o Renato precisou sair para sua aula às 14h. O Carlos havia chegado bem atrasado e eu também tinha aula às $14 \mathrm{~h}$, mas acabei ficando um pouco além. Então, eu estava apreensiva com a hora. Combinamos sobre o formato do seminário enquanto o Renato ainda estava presente: usaremos - todos de acordo - alguns trechos do documentário Santiago e faremos uma simulação. Aí eu já me preparava para sair quando o Carlos questionou sobre o conteúdo da exposição. Eu não devia ter prosseguido, pois era minha hora de ir, mas acabei cedendo e ele começou a falar sobre a diferença entre a pesquisa-ação e pesquisa participante. Eu disse que era a ação (a ser apresentada no seminário). Então ele começou a questionar e me perguntou: "você leu mesmo o texto?! Não é isso que o texto está falando! Você não sabe a diferença entre pesquisa-ação e participante?!". Fiquei irritada com aquela cobrança. Essa não era a minha dúvida. Quando li o texto, na primeira vez, nem me importei com isso. Por que eu deveria saber isso!? Então refleti sobre minha pesquisa. Pensei o quanto em sala de aula já fui e sou cobrada em saber coisas que não são do meu interesse. Pensei o quanto me 
cobro em saber detalhes minuciosos de um assunto, filigranas mesmo, para responder dúvidas que não são minhas. Pensei o quanto faço isso também e que já agi comigo e com meus professores exatamente como o Carlos agiu comigo. Pensei ainda que tudo isso tem desdobramentos em formato de dúvidas: será que a imagem de professor, o detentor do saber, contribui para esta atitude? Será que a imagem que construímos do que é ser professor permite que nós, eu e o Carlos, tenhamos essa reação? Ou seja, será que o professor - sabedor de tudo - tem que me ensinar? Isso não corrobora minha postura passiva diante do conhecimento... é ele professor que tem que me ensinar?! Estas questões, tão elaboradas por impulso e ainda confusas, expressam em parte uma descoberta (autodescoberta) que contou com o outro (na figura do Carlos) para me mostrar algo bem irritante de ver no meu comportamento, no meu imaginário. Mas, ao mesmo tempo, é dessa autodescoberta que pode emergir uma atitude mais ativa perante o ato de conhecer (e também ante aos meus professores) e, por consequência, uma compreensão maior em relação à cobrança dos alunos. Afinal, é trabalhoso assumir seu processo de conhecer ativamente e muitos de nós, enquanto estudantes, nos irritamos com os professores que não nos dão facilmente o saber (Diário da pesquisadora, em 17 de março de 2012).

No processo de ensino-aprendizagem não é só o aluno que recebe, o professor também. Daí porque não é só o aluno que espera, o professor também. Gostaria de saber de onde vem essa nossa atitude passiva de ficar esperando o outro nos ensinar. Por que não construímos juntos? (Diário da pesquisadora, em 31 de maio de 2012).

Hoje foi disperso na hora da exibição. A pipoca e a água foram responsáveis, mas também o ambiente com os três carros de som fez com que a dispersão alcançasse alto nível. $A$ caixa de som está ótima agora. Mas as crianças estão, parece-me, com resistência de se aproximar dos alunos. Como lidar com isso? Outra coisa que me incomodou foi a postura perdida e passiva de alguns alunos ontem. Vivemos uma tensão. As crianças não queriam o teatro de sombras, mas nós tínhamos planejado realizá-lo. Insisti com os alunos do NL e eles não conseguiram fazer a inserção temática na apresentação das crianças. O fato é que recuamos do nosso planejamento e deixamos as crianças se apresentarem, realizando uma espécie de show de talentos. Filmamos as apresentações, que incluiu uma imitação do cantor Latino e uma trupe de dançarinos. Eu nem conhecia a música. Depois, bem no final é que as crianças se interessaram pela caixa do teatro de sombras... (Diário da pesquisadora, em 10 de março de 2012).

Se no contexto em que atuo a orientação acadêmica é hegemônica, a qual não me instiga ao exercício docente, então me sinto desafiada a buscar outras orientações conceituais a

Revista Digital do LAV - Santa Maria - vol. 11, n. 3, p. 138 - 161 - set./dez. 2018 ISSN 1983 - 7348 http://dx.doi.org/10.5902/1983734832834551 
fim de experimentar outros espaços-tempos formativos para mim e para os/as estudantes com os/as quais partilho as aulas. Neste sentido, me lembro de Miranda (2015b, p. 3233) quando afirma que,

Quando nos deparamos frente à pergunta sobre quais são os desafios para os educadores, especialmente para aqueles que trabalham com a produção cultural de seu tempo, não podemos nos esquecer dos seus questionamentos pessoais. Assim, investigaríamos quase a partir de uma autorreferência. Então podemos perguntar: quais são nossos próprios desafios? Seremos capazes de explicar aos outros nossas preocupações e interesses, nossas dúvidas e discussões? ${ }^{2}$

Ao buscar meus questionamentos, preocupações e interesses pessoais, lembro-me de que quando eu iniciei minha prática docente no ensino superior, em paralelo, participei de uma série de grupos de estudo e oficinas cujas temáticas e metodologias educativas eram de preocupação feminista ${ }^{3}$. Segundo Portella e Gouveia (1999, p. 20),

O movimento feminista criou uma metodologia para ação educativa, atualmente fortemente ancorada na perspectiva de gênero, que pode ser assim descrita: ênfase nas atividades de grupo, no formato participativo e no uso de metodologias que articulam subjetividade e racionalidade, experiência pessoal e conhecimento teórico e técnico.

No trecho acima as autoras argumentam que as metodologias para a ação educativa com as quais tive contato são ancoradas numa perspectiva de gênero, mas o que significa gênero? No esforço de pensá-lo como uma categoria analítica, Scott (1995) alerta para o fato de que gênero tem sido utilizado como sinônimo de mulheres. De acordo com Butler (2003, p. 20, grifos da autora), mulher/mulheres é considerado um termo problemático, mesmo estando no plural, por pretender, mas ser incapaz de denotar uma identidade comum, afinal

Se alguém "é" uma mulher, isso certamente não é tudo o que esse alguém é; o termo não logra ser exaustivo, não porque os traços predefinidos de gênero da "pessoa" transcendam a parafernália específica de seu gênero, mas porque o gênero nem sempre se constituiu de maneira coerente ou consistente nos diferentes contextos históricos, e porque o gênero estabelece interseções com modalidades raciais, classistas, étnicas, sexuais e regionais de

\footnotetext{
2 "Cuando nos ubicamos frente a la pregunta de cuáles son los desafíos para los educadores, especialmente para aquellos que trabajan con la producción cultural de su tiempo, no podemos evadir el cuestionamiento pessoal. Así cuestionaríamos casi la autorreferencia. Entonces nos interrogamos: ?cuáles son nuestros propios desafios? ?Seremos capaces de explicar a otros nuestras preocupaciones y desvelos, nuestras dudas y nuestras discusiones?"

${ }^{3} \mathrm{Em} \mathrm{2002}$, iniciei minha carreira como docente no ensino superior. Em 2003, sou aceita como voluntária na Organização Não Governamental (ONG) feminista Grupo Transas do Corpo, em Goiânia, Goiás. Em 2004 e 2005, trabalho no Grupo como comunicadora. Durante este período, participo das formações oferecidas ao público interno e externo.
}

Revista Digital do LAV - Santa Maria - vol. 11, n. 3, p. 138 - 161 - set./dez. 2018 ISSN 1983 - 7348

http://dx.doi.org/10.5902/1983734832834551 
identidades discursivamente constituídas. Resulta que se tornou impossível separar a noção de "gênero" das interseções políticas e culturais em que invariavelmente ela é produzida e mantida.

Por isso, Butler (2003, p. 37, grifos da autora), interessada nas discussões envolvendo as identidades de gênero, alerta para a complexidade do conceito por ele pressupor uma totalidade da pessoa "jamais plenamente exibida" de modo a sugerir que ao ser utilizado ele "permita múltiplas convergências e divergências, sem obediência a um telos normativo e definidor".

Em outra perspectiva, Scott (1995, p. 86), interessada em discutir gênero como uma categoria analítica, se ocupa em defini-lo a partir de duas proposições, sendo a primeira "o gênero é um elemento constitutivo de relações sociais baseadas nas diferenças percebidas entre os sexos" e a segunda "o gênero é uma forma primária de dar significado às relações de poder".

Para a autora, pensar o conceito de gênero como categoria analítica exige observá-lo nas relações sociais humanas, o que implica em perceber quais sentidos ele oferece para as organizações e a percepção da história e da construção do seu conhecimento. Por isso, a autora agrega à definição acima quatro elementos, sem os quais se torna inviável utilizar o conceito de gênero como categoria analítica. São eles:

- o primeiro elemento são os símbolos culturalmente disponíveis que evocam representações de poder;

- o segundo são os conceitos normativos com os quais interpreto o significado destes símbolos;

- o terceiro diz respeito à largueza das relações de gênero, pois elas não são apenas do domínio do doméstico ou dos assuntos exclusivos da/s mulher/es. Primeiramente porque a autora observa que se tais assuntos são tidos por femininos só o são por estar em relação com os masculinos. Em segundo, porque em todos os campos (seja o político, o econômico, e até mesmo a educação superior, como é o caso desta pesquisa) existem relações de gênero que contribuem para construção dos significados;

- o último elemento é a observação de que a identidade (de gênero) é também subjetiva, por isso, sua construção é feita em relação às atividades, organizações e representações sociais e históricas entre homens e mulheres. Em resumo, a autora pensa gênero como um campo onde o poder é articulado, por isso é preciso considerar os quatro elementos acima para sua utilização como categoria de análise. 
As vivências formativas de gênero marcaram minha docência não apenas na perspectiva das ações metodológicas, mas especialmente quanto aos seus princípios teóricos. Muitos destes reverberam no meu modo de pensar a minha própria formação e a dos/as estudantes. Por ter tido contato com este conhecimento de modo vivencial, nas formações dos grupos de estudos e oficinas, tornou-se imprescindível abarcar na minha ação docente alguns princípios esquematizados por Portella e Gouveia (1999) para orientar a prática político-educativa feminista:

1) A ação educativa é também política, pois objetiva interferir nas situações de desigualdade de gênero, estimulando a autonomia e o empoderamento das participantes. 2) No entanto, reconhece que a ação educativa é processual, por isso requer um relacionamento contínuo para além de uma única oficina ou formação.

3) Baseado no método de Paulo Freire, o processo político-educativo parte da realidade das participantes cujo conhecimento se dá por meio de diagnóstico, levantamentos, estudos, da experiência prática com os grupos-alvo, de processos coletivos de construção de conhecimento. Refletir sobre relações de subordinação requer observar a experiência das participantes e a autodescoberta das mesmas.

4) Decorrendo do princípio anterior, as formações precisam considerar o conhecimento e a experiência acumulada das participantes, sua história pessoal e coletiva. Por meio do estímulo à participação ativa nas atividades e da utilização das informações das experiências das participantes como conteúdo, obtém-se uma relação de mão dupla no processo de aprendizagem.

5) Ainda sobre o princípio anterior, é preciso considerar que além do grupo, o/a educador/a também possui conhecimento e experiência acumulada de modo a trazer para o grupo: informações e análises sistematizadas e a orientá-lo no processo por meio da coordenação das atividades e da articulação entre as informações e as experiências.

6) As ações educativas objetivam democratizar o acesso ao conhecimento acumulado e sistematizado em campos temáticos diversos, o que implica em considerar, no mínimo: a experiência e opinião dos/as educandos/as e educador/a em articulação com análises e informações oriundas de centros de pesquisa e universidades.

7) O processo político-educativo é um processo de troca em que as diversas fontes de conhecimento, saberes e experiência têm a mesma importância, significando que tanto educador/a quanto educando/a tenham espaço para opinar efetivamente e contribuir para sua condução.

8) No processo político-educativo estão em jogo relações de poder, baseadas em relações sociais, de modo que é preciso considerar as diferenças (sexual, raça, classe, 
etária) para incluí-las (sem estimular o confronto) na atividade educativa ao invés de escamoteá-las.

9) A aprendizagem envolve o sujeito por inteiro: sua história pessoal, crenças, afetos e desejos e não apenas o intelecto. Isso implica em incluir nas atividades conteúdo da esfera privada, emocional e subjetiva.

Voltando aos meus questionamentos, preocupações e interesses pessoais, após quase três anos em contato com estas formações, suas metodologias e princípios teóricos, me desafia o espaço-tempo de professora na perspectiva do que García (1999) define como orientação conceitual acadêmica. Não me interessa vivenciar este espaço-tempo, mas por quê?

Para García (1999) a orientação acadêmica é hegemônica no ensino superior. O autor a define como a orientação que enfatiza o/a professor/a como um/a especialista numa área ou em determinadas disciplinas, sendo o conteúdo extremamente valorizado em detrimento das práticas pedagógicas. Neste contexto, a imagem do/a conferencista ao redor do qual os/as estudantes ouvem sua exposição me vem à mente. Bem como todos os jogos que envolvem esta ação.

A imagem deste/a conferencista é que me acompanha quando cito nos trechos do meu diário a figura do/a professor/a detentor/a do saber. Colocar-me neste lugar incomodame, pois sei que não detenho o saber, sei que ele me escapa uma vez que é imenso. Mesmo sobre uma disciplina ou área em que seja especialista, sei que há perspectivas que não conheço.

Apesar disso, é no ensino superior em que atuo e nele a orientação conceitual acadêmica é hegemônica. É também ali que recebo perguntas dos/as estudantes como a que recebi do colega de curso, o Carlos, exercendo seu poder. A pergunta "como você não sabe isso?!" reflete desconhecimento, pois supõe que o conhecimento é todo ele alcançável e que o/a professor/a deve detê-lo por inteiro. Mas ao mesmo tempo demonstra um exercício de subjugação de quem faz a pergunta para quem ela é dirigida.

No ensino superior, o/a estudante exerce seu poder fazendo esse tipo de pergunta, que é um jogo de cobrança/teste ao/a professor/a. Também o/a professor/a joga ao exercer seu poder sobre o/a estudante devolvendo-Ihe perguntas/cobranças/testes desta natureza nas provas, nas aulas, nas atividades. Enfim, a orientação acadêmica possibilita a especialização, traduzida pela verticalização dos conteúdos, mas também uma subjugação hierárquica (ora vinda do/a professor/a, ora do/a estudante) por meio de cobranças/testes mais competitivos do que instigantes.

Revista Digital do LAV - Santa Maria - vol. 11, n. 3, p. 138 - 161 - set./dez. 2018 ISSN 1983 - 7348 
Além disso, ao vivenciar formações em grupos feministas ligadas às discussões de educação em gênero ${ }^{4}$, tive acesso a leituras e debates que questionavam a hierarquia entre o conhecimento pessoal, privado, tradicional e o escolar-acadêmico. Assim, pude refletir por meio de ações formativas a relativização destas hierarquias e das suas reverberações, como as hierarquias entre o teórico e o prático. Também nas formações vivenciadas naqueles grupos tive a ação participada estimulada de modo a perceber-me como aquela que primeiramente dirige os processos de construção de conhecimento, independente de quem esteja na condução da formação.

Contudo, observo outra questão: quando escrevi este trecho do diário, a imagem do professor como o detentor do saber que me vinha à mente era masculina. Por isso, não fiz uso da escrita inclusiva, neste trecho. Não construí essa imagem para ambos os gêneros, apenas me vinha à mente um professor, homem, rodeado de estudantes a ouvi-lo. Será que a orientação acadêmica, seus princípios e jogos de poder estimulam certa exclusão de gênero? $E$, ainda, será que não me sentir confortável ou não me perceber como pertencente a esta orientação traduz uma questão de gênero na academia?

Mesmo que eu não tenha respostas para estas perguntas, elas me dão pistas para uma sensação de inadequação docente com a academia. Assim, as vivências envolvendo ações educativas em gênero e as metodologias feministas são para essa investigação uma referência fundamental sem a qual o incômodo motivador para iniciá-la não teria sequer sido traduzido. Em outras palavras, por ter vivenciado processos educativos embrenhados de solidariedade feminista é que me causa estranheza o modelo de ensino baseado na orientação acadêmica.

Contudo, a estranheza não está centrada apenas em uma ausência de solidariedade, mas na presença da marcação hierárquica e dicotômica entre saberes: o público acima e distante do privado, o teórico do prático, o popular/tradicional do acadêmico, o professor do/a estudante etc. Desse modo, há uma busca por uma ação docente que abre espaço para questionar essas dicotomias e hierarquias, considerando pensá-las continuamente com os sujeitos envolvidos nos dois NLs.

Essas marcações estão embrenhadas na cultura, sendo disseminadas por meio das diversas linguagens com as quais nos comunicamos, dentre elas o audiovisual, objeto de estudo nos dois NLs. Neste sentido, essa investigação buscou experimentar uma articulação de saberes e fazeres audiovisuais referenciadas em vivências pessoais que

\footnotetext{
${ }^{4}$ Grupo Transas do Corpo, em Goiânia, Goiás, e suas parceiras de formação.
} 
construí em grupo de mulheres envolvendo metodologias e ações educativas em igualdade de gênero, raça, sexo e classe.

Para tanto, o sentido dos saberes éticos presente na problematização da pesquisa abarca uma ação docente que busca manter aberto um espaço para a construção de relações pautadas pela igualdade do dizer e ouvir em grupo, sendo os sujeitos participantes quem quer que sejam. Esse espaço eu supunha, desde o início, seria prenhe de tensões e contradições. Apesar disso, reconhecia a potência dos seus saberes caso eles fossem problematizados pelos/as participantes continuamente. Em outras palavras, os combinados que estabelecemos continuamente para a manutenção desse espaço configurou-se como saberes éticos.

Assim como os saberes éticos foram construídos em grupo, o processo de construção de conhecimento audiovisual também, demandando questionamentos: se já sei que o conhecimento não é todo alcançável, não me interessa sugerir que ele seja aos/as estudantes. Não me interessa exercer esse poder, pois desconfio da sua validade. Não me interessa vivenciar este espaço-tempo docente porque observo que ele tende a reforçar uma postura passiva diante do conhecimento. Busco, com esta investigação, reconhecer e estimular tanto em mim, quanto nos/as estudantes, modos de conhecer por meio da ação conjunta, ou melhor, da interação formativa ou interformação. Reconheço que esse é um incômodo pautado em uma ética de trocas.

Observo, nos trechos citados do meu diário, que a postura estudantil passiva, torna a ação docente pouco instigante para mim. Afinal, assim como o/a estudante tem expectativas diante de um novo curso, eu como professora também as tenho. É neste sentido que trago alguns pensamentos diante de uma situação de divergência: a insistência das crianças do projeto de extensão Pezinho de Jatobá em realizar um show de talentos.

É preciso explicar melhor o ocorrido. No NL Saberes Audiovisuais Colaborativos, em 2012/1, os/as estudantes tinham aulas no espaço físico da universidade e também na sala do projeto de extensão Pezinho de Jatobá. O plano de ensino foi pensado para articular estes dois espaços atendendo um duplo público (os/as estudantes da disciplina e os/as participantes do projeto de extensão) por meio da ação de aprender e ensinar audiovisual uns aos outros de modo participado. Assim, das aulas que ocorriam na universidade surgiam propostas de exibições e experimentações audiovisuais que posteriormente eram submetidas aos/as participantes do Pezinho, gerando uma programação para o próximo encontro. 
Especificamente neste dia, houve um desafio: os/as participantes do Pezinho subverteram a programação do que chamamos de teatro de sombras preferindo uma espécie de show de talentos aos moldes televisivos e se prepararam (ensaiaram uma música de sucesso na época, pintaram o cabelo imitando o cantor Latino, pensaram em um figurino, fizeram a maquiagem, trouxeram a trilha sonora em um pendrive etc.).

Quando chegamos à sala do projeto com o cenário do teatro de sombras, não houve interesse por essa atividade e os/as estudantes não tiveram reação nem conseguiram negociar as duas propostas. Chamaram-me à parte e relataram o que estava acontecendo demonstrando irritação, sentimento de fracasso e inação.

Considerando que essa era uma das nossas primeiras experimentações entre professorapesquisadora, estudantes e participantes do Pezinho, estes que eram em sua maioria crianças, desafiaram a proposta levada pelos primeiros, gerando uma solução de problema diante do qual os/as estudantes se irritaram e cobraram de mim, professora, uma solução a fim de mantermos o planejado. A minha reação, muito semelhante à pergunta do meu colega Carlos, foi no primeiro momento de irritação: "Eu? Por que eu devo garantir o planejado?" O silêncio pairou. "Façamos juntos uma negociação", eu disse depois de já ter perdido a paciência.

"Quem propõe uma solução?", perguntei aos/as estudantes. Depois de algumas propostas e certo nervosismo, uma estudante sugeriu que abríssemos mão da atividade que fora planejada em conjunto para aquela manhã, sob a condição de que a retomaríamos no encontro seguinte. "Estamos de acordo? - Sim. Sim? Então façamos assim".

As imagens abaixo são frames (quadros) capturados de alguns vídeos que os/as estudantes fizeram durante este dia de aula. É possível perceber nas figuras 2,3 e 4 o entusiasmo dos/as participantes do Pezinho para esta apresentação, que eles chamaram de Show de Talentos, subvertendo o teatro de sombras, que tínhamos programado em grupo. A iniciativa da maquiagem, o uso de tocas e chapéu, o tecido preto substituindo a cortina, a coreografia e a trilha sonora foi deles/as. Só depois que se apresentaram é que o teatro de sombras gerou interesse, vide figura 5 . 


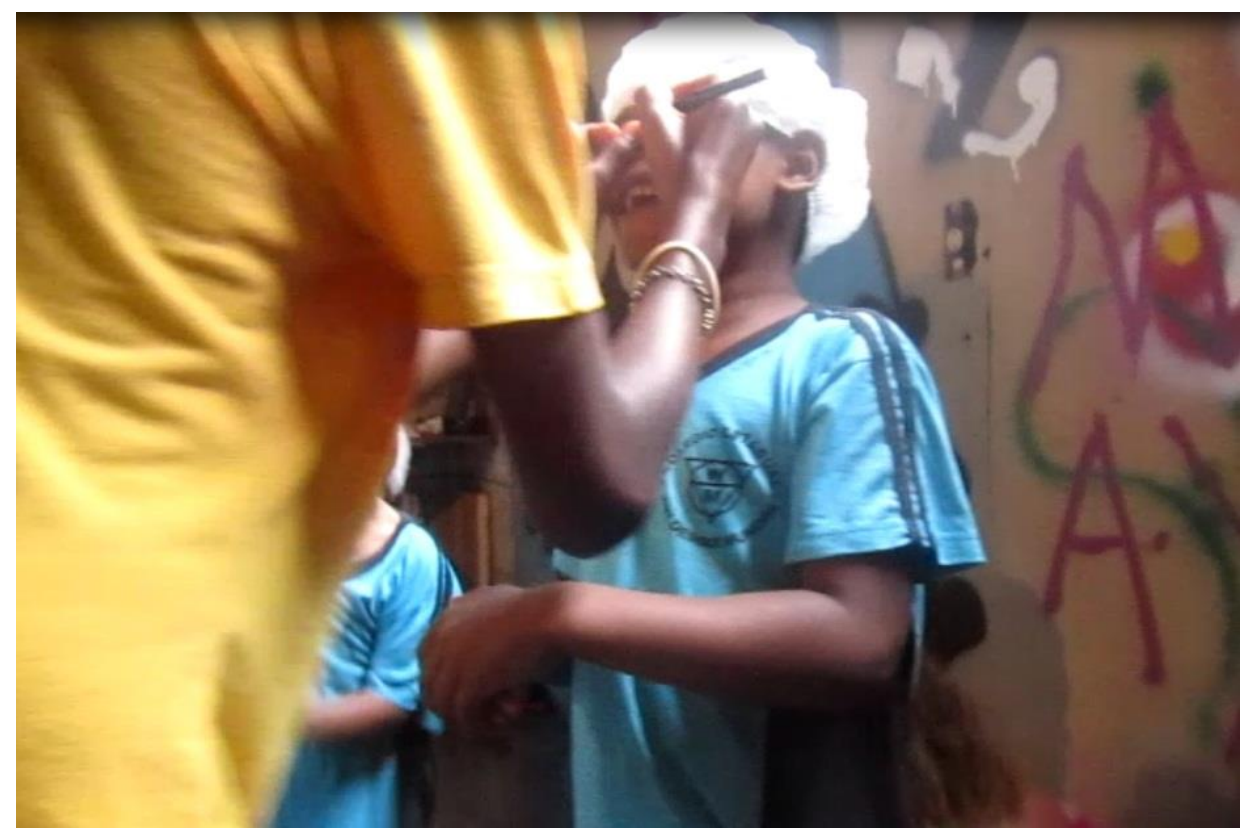

Figura 02. Participante do Pezinho faz a maquiagem em outro (frame de vídeo de Cinara Flávia)

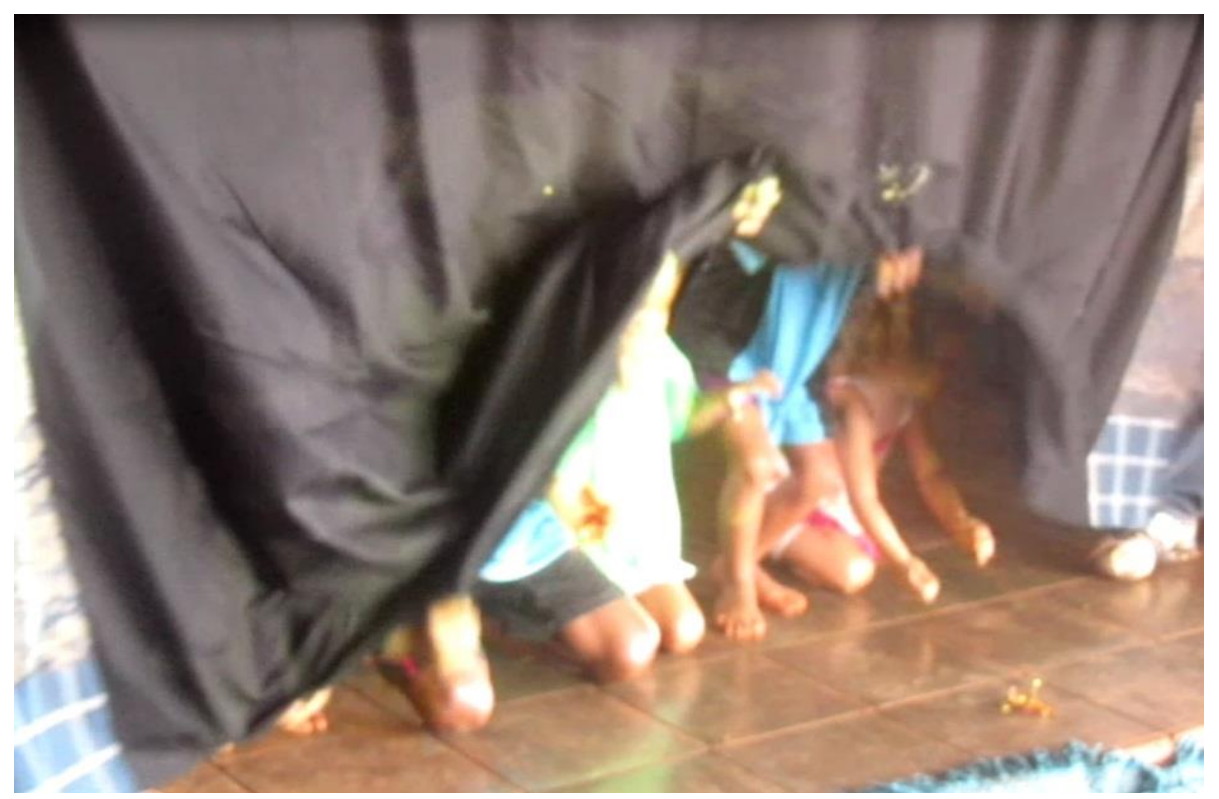

Figura 03. Sobem as cortinas... Início do Show de Talentos dos/as participantes do Pezinho

(frame de vídeo de Simone Passos) 


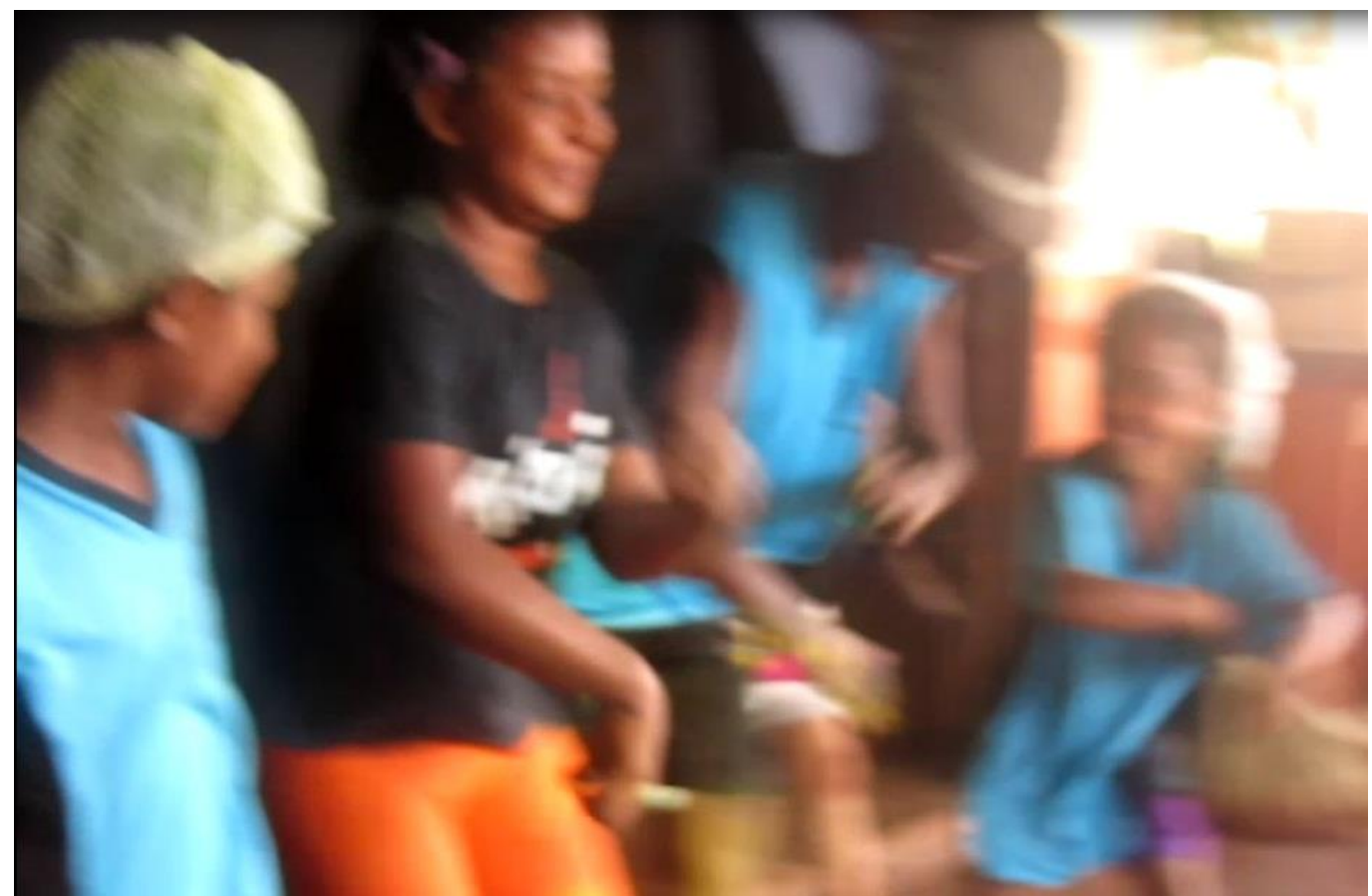

Figura 04. O líder (de chapéu) representa o cantor brasileiro Latino e seus dançarinos (frame de vídeo de Simone Passos)

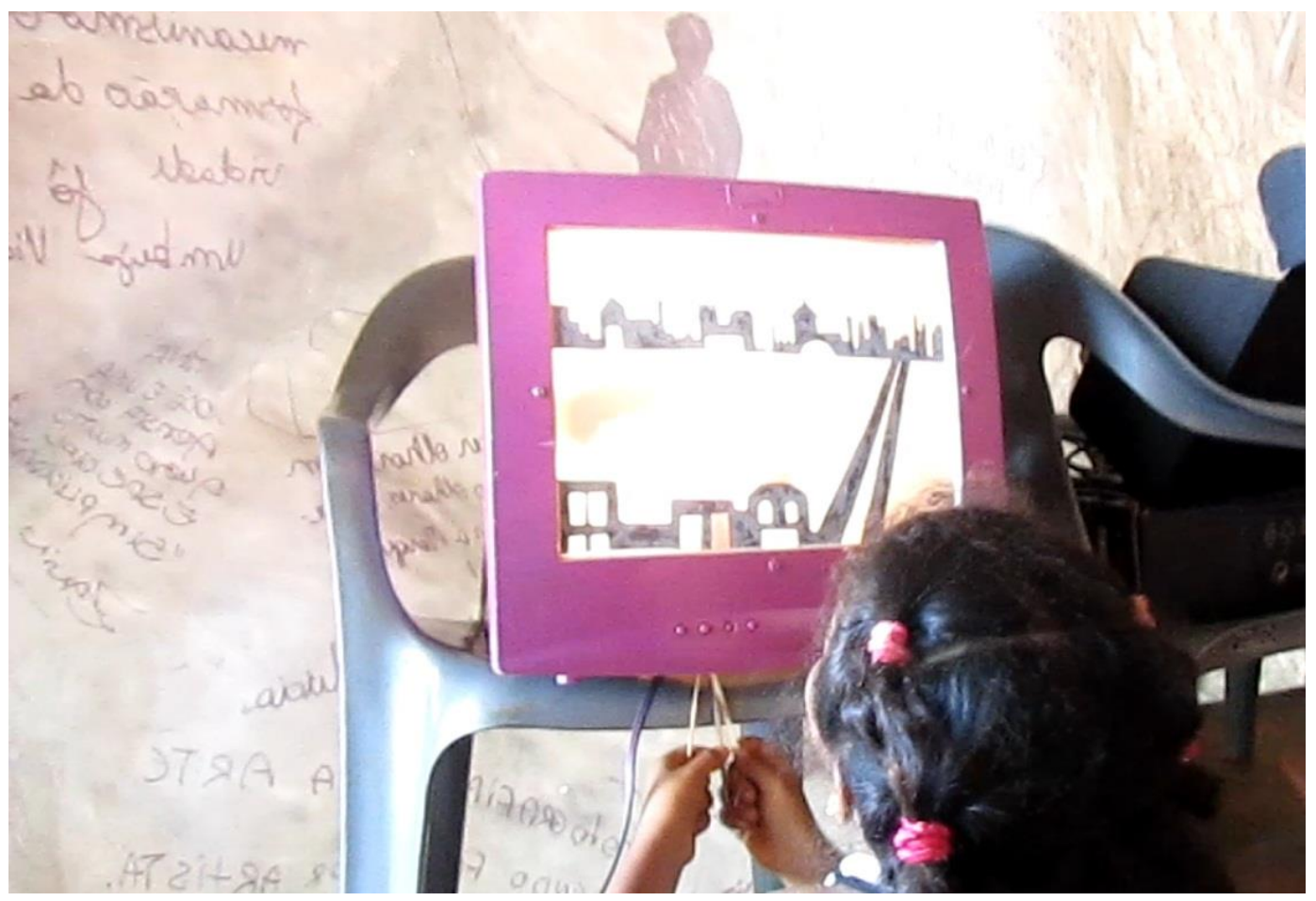

Figura 05. Depois do Show de Talentos... Aí o teatro de sombras gerou curiosidade (frame do vídeo de Simone Passos)

Nos trechos dos diários de aula de estudantes, a perspectiva do ocorrido foi, 
A atividade de hoje seria sobre o jogo de sombras, uma estorinha que seria contada através de um teatro de sombras. Os meninos nos surpreenderam. Na verdade, me surpreenderam ainda mais. Eles com a liderança do Pedro fizeram um número com danças de sua própria cultura. O que eu estranhei no começo, cheguei a ficar nervoso, mas que no final valeu a pena. Nós constatamos cada vez mais o poder criativo deles, sua resistência. Temos que aprender que tudo tem que ser negociado, não podemos simplesmente impor nossa vontade (Diário de Eduardo Luiz, em 24 de março de 2012).

Eles assistiram os desenhos, porém, na hora de realizarmos as atividades, eles tomaram conta do espetáculo: os "posicionamentos" se inverteram e eles fizeram do jeito deles! Se soltaram, se expressaram... havia até o diretor do teatro deles. Tinham até figurino... encantadores! Enfim, apesar de não ter sido como a professora havia planejado as atividades, acho que aprendemos muito mais com eles do que eles conosco (Diário de Cinara Flávia, em 24 de março de 2012).

No sábado, dia 24/03, foi uma surpresa, pois a professora havia preparado um "teatro de sombras" (experimento) e fomos surpreendidos com atitudes de desinteresse por parte das crianças, pois elas haviam preparado apresentações de música e uma contação de histórias. Eu gravei a contação. Foi diferente o manuseio da câmera, o levantar, abaixar, filmar de lado. [...] Obs.: Sugeri à professora que estabelecesse com as crianças combinados. Nós cederíamos hoje, mas no próximo encontro faremos o que tínhamos proposto (Diário de Simone Passos, em 24 de março de 2012, grifos da autora).

Logo depois, o propósito do experimento do dia que era o "Teatro de Sombras" foi negociado com os meninos, pois eles estavam super entusiasmados com a apresentação de dança e contação de história que haviam preparado há alguns dias. Deixamos o "Teatro de Sombras" para a próxima aula (Diário de Rosana Sodré, em 24 de março de 2012, grifos da autora).

A partir dos trechos acima, observo que houve pouca apreensão de que as atividades (chamadas de experimentos) eram pensadas em conjunto. Noto isso na atribuição da autoria do experimento: em quase todos os trechos acima a proposta vem de mim, a professora, ou de uma origem impessoal "o propósito do experimento do dia". Talvez porque já estivessem sugeridas no plano de ensino da disciplina (mesmo que a título de sugestão, podendo ser substituídas por outros experimentos), talvez porque ainda seja raro negociar no contexto acadêmico os processos de construção de conhecimento. Uma sinalização desta raridade está no estranhamento de Eduardo diante da situação, que foi expresso no nervosismo e na reflexão de que é preciso negociar em detrimento de impor.

Revista Digital do LAV - Santa Maria - vol. 11, n. 3, p. 138 - 161 - set./dez. 2018 ISSN 1983 - 7348 http://dx.doi.org/10.5902/1983734832834551 
Outro estranhamento que me chamou a atenção nos trechos acima reflete sobre os "'posicionamentos' [que] se inverteram e eles fizeram do jeito deles!", no diário de Cinara. Apreendo da sua surpresa que existe o posicionamento de quem estava ali recebendo (os/as participantes do Pezinho de Jatobá) e de quem está propondo (nós da universidade). O fato de ter havido uma inversão, para ela, foge à regra e é digna de destaque no seu texto. Na sua perspectiva, segundo a regra quem dirige goza de um posicionamento ativo e quem é dirigido assume uma postura passiva.

\section{Considerações finais}

Este texto apresenta resultados de uma pesquisa cujo objeto é a minha ação docente envolvendo o audiovisual, em uma escola de Comunicação Social, no ensino superior. Dada a tímida atenção que tal campo oferece ao ensino, busco em outro, a saber, na Educação da Cultura Visual, aporte teórico e metodológico para investigar sobre processos interformativos que relacionem o meu aperfeiçoamento como professora-pesquisadora e a aprendizagem audiovisual de estudantes que aceitaram colaborar com essa descoberta.

Quanto a delimitação teórica, Dias (2011) discute significação da Educação da Cultura Visual, que é traduzida por uma diversidade de abordagens do estudo da arte, indo do exercício de poética, de apreciação à construção de crítica, de modo a privilegiar uma amplitude formativa. Apesar do debate estar situado no ensino de artes visuais, apropriarme desta perspectiva para refletir sobre a formação audiovisual, em uma escola de Comunicação Social, torna-se profícuo na medida em que o recorte empírico apresentado traz desafios.

Um destes é o alargamento de objetivos e frentes de interesses de uma disciplina, como a analisada neste NL, campo da pesquisa. Observo que, em escolas de Comunicação Social, a prática de ensino sugere certa dicotomia entre disciplinas de produção, práticas versus de apreciação e construção de crítica, sendo estas últimas de cunho teórico. A compartimentação entre o prático e o teórico, neste contexto de ensino, desafia uma proposta que buscou privilegiar processos de criação em paralelo aos de apreciação e construção crítica. É como se a carga horária de 64 horas/aula fosse insuficiente para abarcar interesses tão diversos, dando conta dos objetivos de aprendizados de estudantes envolvidos e de membros do projeto de extensão.

Ao adotar a dupla função de professora-pesquisadora, a pesquisa vincula-se ainda aos estudos de Formação de Professores/as. Apesar disso, há a necessidade de constantemente construir adaptações e apropriações dos conceitos utilizados, de modo a contextualizar os valores, as compartimentações e separatismos que emergem no campo

Revista Digital do LAV - Santa Maria - vol. 11, n. 3, p. 138 - 161 - set./dez. 2018 ISSN 1983 - 7348 
em que o NL foi oferecido. Com Miranda (2015b), reflito que incluir na reflexão o meu próprio percurso, isto é, aquilo que constitui minha autorreferência é algo que auxilia o exercício de compreender o que significa ser professora no ensino superior.

Descubro, a partir dessa indagação, que meu contato com educadoras feministas é fundamental para questionar um ser professor universitário estranho a mim, professora. Certamente porque essa imagem de um professor especialista, detentor do saber é masculina e que eu não me identifico com ela. Além disso, há uma recusa em reproduzir a falsa noção de que o professor universitário seja capaz de um saber enciclopédico, mesmo dentro da sua especialidade.

Se, de um lado, os princípios teóricos e as metodologias feministas reverberam na minha ação docente, de outro, reconheço que eles são gerados e praticados em espaços do movimento de mulheres, espaço este distinto do acadêmico. Isso implica em compreender que não se trata simplesmente de trazê-los para dentro da universidade e fazer uso destas metodologias nas minhas aulas. Observo que é preciso mais cuidado para a apropriação de um saber que objetiva intervenções sociais de cunho tão visceral.

Ao adotar como abordagem metodológica a reflexão-ação, que se inspira na pesquisa-ação de Thiollent (1985), dialogo com o interesse de investigar sobre meu fazer docente, agindo e refletindo sobre ele de modo cíclico e contínuo com estudantes e participantes do projeto de extensão vinculado ao campo da pesquisa. Neste contexto e a partir de um repertório imbricado de metodologias feministas, avalio que o prático é evidentemente indissociável do teórico, assim como já propôs Dias (2011).

Neste sentido, o estranhamento de estudantes quanto ao acontecido no campo da pesquisa, registrados nos seus diários, demonstram uma não apreensão de que a proposta da disciplina estava aberta a intervenção discente e ainda aos membros do projeto de extensão. Os trechos dos diários revelam que pouco houve compreensão de uma construção processual e desenvolvida em grupo e expressam a cristalização de um modo de construção de conhecimento impositiva, com o qual não me interessa partilhar. Se esse modo de construção de conhecimento não me interessa, qual seriam outros modos? Quais suas orientações conceituais? E como minha ação docente se apropria deles? A busca por essas respostas será o assunto para um próximo texto.

\section{Referências}

BUTLER, J. Sujeitos do sexo/gênero/desejo. In: Problemas de gênero: feminismo e subversão da identidade. Rio de Janeiro: Civilização Brasileira, 2003. p. 15-37. 
CARVALHO, R. I. B. de. A prática pedagógica do bacharel professor da área de Comunicação Social. 2012. Tese (Doutorado em Educação) - Faculdade de Educação, Universidade de Brasília, Brasília, 2012.

DEWEY, J. The philosophy of Jonh Dewey. Two volumes in one: The sctruture of experience/The lived experience. Chicago: The University of Chicago Press, 1981.

DIAS, B. O i/mundo da educação em cultura visual. Brasília: Ed. da Pós-graduação em Arte da UnB, 2011.

DUBOIS, P. Cinema, vídeo, Godard. São Paulo: Cosac Naify, 2004.

GARCÍA, C. M. Formação de professores: para uma mudança educativa. Porto: Porto Editora, 1999.

MARTINS, A.F. Arena aberta de combates, também alcunhada de Cultura Visual anotações para uma Aula de Metodologia de Pesquisa. In: MARTINS, R.; TOURINHO, I. (Orgs.). Cultura das imagens: desafios para a arte e para a educação. Santa Maria: Ed. da UFSM, 2012. p. 207-230.

MARTINS, R.; TOURINHO, I. Reflexividade e pesquisa empírica nos infiltráveis caminhos da cultura visual. In: (Orgs.). Processos e práticas de pesquisa em cultura visual e educação. Santa Maria: Ed. da UFSM, 2013. p. 61-76.

MIRANDA, F. Imágenes, artefactos visuales y tecnologias: condiciones y relaciones. In: ; VICCI; G. (Orgs.). Artes visuales: tecnologías, contenidos y aprendizajes en la cultura visual y el arte. Montevideo: Ediciones Santillana, 2015a. p.11-24.

MIRANDA, F. Los aprendizajes con relación al arte y la cultura visual. In: ; VICCI; G. (Orgs.). Artes visuales: tecnologías, contenidos y aprendizajes en la cultura visual y el arte. Montevideo: Ediciones Santillana, 2015b. p. 25-58.

OLIVEIRA, M.O. de. O que pode um diário de aula? In: MARTINS, R.; TOURINHO, I. (Orgs.). Processos e práticas de pesquisa em cultura visual e educação. Santa Maria: Ed. da UFSM, 2013. p. 225-236.

OLIVEIRA, M.O. de. Por uma abordagem narrativa e autobiográfica: diários de aula como foco de investigação. In: MARTINS, R.; TOURINHO, I. (Orgs.). Educação da Cultura Visual: conceitos e contextos. Santa Maria: Ed. da UFSM, 2011. p. 175-190.

Revista Digital do LAV - Santa Maria - vol. 11, n. 3, p. 138 - 161 - set./dez. 2018 ISSN 1983 - 7348 http://dx.doi.org/10.5902/1983734832834551 
PORTELLA, A.P.; GOUVEIA, T. Introdução: feminismo, educação e gênero. In: Ideias e dinâmicas para trabalhar com gênero. Recife: SOS Corpo Gênero e Cidadania, 1999. (Metodologia SOS Corpo).

SCOTT, J. Gênero: uma categoria útil de análise histórica. Educação e Realidade, Ano 20, n. 2, p. 71-99, jul./dez.1995.

THIOLLENT, M. Notas para o debate sobre pesquisa-ação. In: BRANDÃO, C.R. (Org.). Repensando a pesquisa participante. São Paulo: Brasiliense, 1985. p. 82-103.

\footnotetext{
i Pós-doutorado em Estudos Culturais (PACC/ UFRJ). Doutorado em Arte e Cultura Visual (PPGACV/ FAV / UFG). Professora-pesquisadora da Faculdade de Informação e Comunicação (FIC) e no Programa de Pós-Graduação Interdisciplinar em Performances Culturais (PPGIPC) da Universidade Federal de Goiás (UFG). É vinculada ao Núcleo de Pesquisa em Teoria da Imagem (NPTI / PRPG-UFG / CNPq). E-mail: satlerlara@gmail.com
}

Como citar esse artigo:

SATLER; Lara Lima. Diretores/as em ação: formação audiovisual atravessada por metodologias feministas. Revista Digital do LAV, Santa Maria: UFSM, v. 11, n. 3, p. 138161, set./dez. 2018. 